\title{
First Nations people with diabetes in Ontario: methods for a longitudinal population-based cohort study
}

\author{
Morgan Slater PhD, Michael E. Green MD MPH, Baiju Shah MD PhD, Shahriar Khan MSc, \\ Carmen R. Jones, Roseanne Sutherland, Kristen Jacklin PhD, Jennifer D. Walker PhD
}

See related research article by Chu and colleagues at www.cmaj.ca/lookup/doi/10.1503/cmaj.190899

\section{Abstract}

Background: To improve diabetes care, First Nations leaders and others need access to population-level health data. We provide details of the collaborative methods we used to describe the prevalence and incidence of diabetes in First Nations people in Ontario and present demographic data for this population compared to the rest of the Ontario population.

Methods: To identify the population of First Nations people and other people in Ontario, we created annual cohorts of the Ontario population for each year between Apr. 1, 1995, and Mar. 31, 2015. Through a partnership between First Nations and academic researchers, we linked provincial population-based health administrative data stored at ICES with the Indian Register, which identifies all Status First Nations people. Our collaborative process was guided by the First Nations principles of ownership, control, access and possession (OCAP).

Results: Demographic characteristics for the 2014/15 cohort $(n=13406684)$ are presented here. The cohort includes 158241 Status First Nations people and 13248443 other people living in Ontario. Using postal codes, we were able to identify virtually all (99.9\%) First Nations people in Ontario as living in $(n=55311)$ or outside $(n=102889)$ a First Nations community. First Nations people were younger and more likely to live in semiurban or rural areas than the rest of Ontario's population.

Interpretation: The collaborative methodology used in this study is applicable to many jurisdictions working with Indigenous groups who have access to similar data. The Ontario cohort defined here is being used to conduct analyses of health outcomes and use of health care services among First Nations people with diabetes in Ontario.

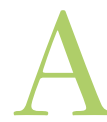

s noted in the 2018 clinical practice guidelines, ${ }^{1}$ Diabetes Canada reported that 3.4 million Canadians were estimated to be living with diabetes in 2016; by 2025 , it is expected that the prevalence of diabetes will have increased by $44 \%$. This increase is likely due to a number of individual-level factors such as obesity, aging, ethnicity, lifestyle and socioeconomic status, ${ }^{2-7}$ environmental factors ${ }^{8}$ and decreasing mortality rates. ${ }^{9-13}$ Among First Nations people, the burden of diabetes is disproportionate: ${ }^{14,15}$ the lifetime risk of diabetes was recently estimated to be 8 in 10 for First Nations adults ( $>18 \mathrm{yr}$ ), compared to 5 in 10 for non-First Nations people. ${ }^{16}$ Prevalence rates are 3-5 times higher among First Nations people than other Canadians, ${ }^{17}$ and diabetes develops at younger ages, progresses more rapidly and has higher complication rates among First Nations people. . $^{16,18,19}$

First Nations people in Canada continue to experience health inequities related to the ongoing impacts of colonization. ${ }^{15,20,21}$ This history has contributed to poverty and mar- ginalization and has resulted in major disparities in health status and outcomes reported for decades. ${ }^{15,22,23}$ Despite these persistent health inequities, First Nations people remain resilient in working toward healing. ${ }^{24}$ To understand the health of their communities and advocate for services within a complex and fragmented health care system, ${ }^{25,26}$ First Nations leaders need access to population-level data.

Competing interests: Michael Green reports a grant from the Ontario SPOR SUPPORT Unit during the conduct of the study and consulting fees from the First Nations and Inuit Health Branch, Health Canada, outside the submitted work. No other competing interests were declared.

This article has been peer reviewed.

Correspondence to: Jennifer Walker, jenniferwalker@laurentian.ca CMAJ Open 2019. DOI:10.9778/cmajo.20190096 
Little is known about the health care experience of First Nations people with diabetes in Ontario. In 2003, an analysis of prevalence, incidence, mortality and hospital admissions related to diabetes relied on identifying First Nations communities through postal codes, which captured only 7\% of First Nations people in Ontario. ${ }^{27}$ Recent initiatives at ICES, where Ontario's public health services data sets are stored, linked and used for research, have enabled the identification of Status First Nations people in Ontario, within guidelines established to ensure First Nations data sovereignty. ${ }^{28,29}$ As a result, we were able to link ICES data sets on disease incidence, demographic characteristics and geography with a data set of registered First Nations people in Canada, which allowed us to collaboratively perform in-depth analyses of health outcomes and use of health care services among First Nations people with diabetes in the province. These analyses are part of a larger, mixed-methods study to describe the landscape of diabetes in First Nations communities across Ontario (Appendix 1, available at www. cmajopen.ca/content/7/4/E680/suppl/DC1).

In this manuscript, we explain the partnership and datagovernance principles guiding the analyses of the administrative health data that we are using to compare the prevalence and incidence of diabetes among First Nations people to those among the rest of the Ontario population between 1995/96 and 2014/15. We describe how we identified First Nations people in Ontario and compare their demographic characteristics to those of others living in Ontario. We also describe how we identified First Nations people with diabetes and the analyses we are conducting to compare their disease control, use of health care services and rates of complications to those of the rest of the Ontario population with diabetes. The first such study, focused on cardiovascular disease, has been published. ${ }^{30}$

\section{Methods}

\section{Partnership and collaboration}

This study is a result of a partnership between the Chiefs of Ontario, ICES and researchers across Ontario, coordinated by investigators at Queen's University, Kingston, Ontario, Laurentian University, Sudbury, Ontario, and the University of Minnesota Medical School, Duluth. The collaborative process used for this project has been described elsewhere. ${ }^{31,32}$ The lead academic investigators have long-standing relationships working with First Nations communities. An Indigenous-led approach, based on principles of Indigenous data sovereignty, ${ }^{29}$ was used throughout the work, and our partners at the Chiefs of Ontario were central to directing this work. Initial meetings between the academic research team, senior health staff from the Chiefs of Ontario, an elder and 2 First Nations patient navigators established processes for working together (formalized in a research agreement) and determined the research questions for the project. All team members actively participated as coinvestigators in the conception and design of the work and in data analysis and interpretation. ${ }^{31}$ Our partners at the Chiefs of Ontario are coauthors on all works stemming from this partnership.
In addition, a patient advisory group made up of 7 First Nations people with lived experience of diabetes as a patient or family member provided additional insight. As described elsewhere, ${ }^{31}$ we worked with the Health Coordination Unit, which includes members from various First Nations organizations in the province, to invite members from different communities, acknowledging the diversity of First Nations people in Ontario. The advisory group met twice yearly, providing constructive and meaningful feedback. All members of the advisory group were offered authorship on all publications.

\section{Data governance}

The Chiefs of Ontario and ICES established a datagovernance agreement to ensure First Nations governance of the Indian Register data held at ICES, in accordance with OCAP (ownership, control, access and possession) principles. ${ }^{33}$ In addition, this project was approved by the First Nations Data Governance Committee, which has 7 members from across the province appointed by the Ontario Chiefs Committee on Health. ${ }^{28}$ The committee developed an application process for researchers interested in accessing the Indian Register to identify First Nations people in Ontario or using the Regional Health Survey data. The current project served as a pilot for this application process. The project was also reviewed and approved by the Health Coordination Unit. We provided regular updates and presented findings to the patient advisory group, the Health Coordination Unit and the annual First Nations Health Forum in Ontario before releasing the results elsewhere.

\section{Data sources}

This project used the Ontario population-level health administrative data housed at ICES. ${ }^{34}$ Key to these analyses is the ability to link provincial population-based health information at the individual level with the Indian Register. The Indian Register is maintained by Crown-Indigenous Relations and Northern Affairs Canada and lists all people who are registered as members of a First Nation that is recognized under the Indian Act (i.e., all "Status Indians" or "Registered Indians"). ${ }^{35}$ These data sets (listed in Appendix 2, available at www.cmajopen.ca/ content/7/4/E680/suppl/DC1) were linked by means of unique encoded identifiers and analyzed at ICES.

\section{Study cohort}

We defined 2 study cohorts. The first cohort is the population of First Nations people and other people in Ontario; we report on their characteristics in this manuscript. Second, we identified people with diabetes from within these cohorts. They will be used to estimate the annual prevalence and incidence of diabetes, as well as describe measures of disease control, use of health care services and rates of complications of diabetes. ${ }^{30,32}$

\section{Incidence and prevalence cohorts}

To identify the population of First Nations people and other people in Ontario, we created annual cohorts of the Ontario population for each year between Apr. 1, 1995, and Mar. 31, 
2015. All people from the Registered Persons Database who were Ontario residents eligible for a health card, were alive for the entire year of the cohort (Apr. 1-Mar. 31 of the following year), had had contact with the health care system within the previous 7 years and were aged 105 years or younger were included in the population cohorts. We included all people who were alive at the end of each fiscal year to ensure that all new cases of diabetes were captured.

We used the Indian Register to identify all Status First Nations people in Ontario; all other Ontario residents were considered to be the population of "other people in Ontario." We used a combination of residence codes and postal codes to identify whether a person lived in a First Nations community (i.e., "Indian Reserves"35). Residence codes are unique to each municipality or First Nations community and are recorded in the National Ambulatory Care Reporting System and the Canadian Institute for Health Information Discharge Abstract Database when people are admitted to emergency departments or hospitals. For those who did not have a recorded residence code, we used their postal code from the Registered Persons Database, which includes the address associated with a person's health card, to map their home address to a census subdivision. Most census subdivisions are clearly and exclusively within a First Nations community or outside a First Nations community. We considered First Nations people who lived in the few census subdivisions that included both First Nations communities and other communities to be living in a First Nations community. Through this process, we classified the residence for First Nations people as being in a First Nations community, outside a First Nations community, out-of-province (based on a postal code outside Ontario) or unknown (there was no available residence code or postal code for the person) each year. As the geographic information available in the 1990s has limited reliability, we determined the classification of living in or outside a First Nations community from 2001 onward.

Within each yearly cohort, we established the presence of diabetes through the Ontario Diabetes Database. This data set has been validated against primary care health records and has a reported sensitivity of $86 \%$ and specificity of $97 \% .^{36}$

\section{Diabetes-specific cohorts}

To estimate diabetes-specific outcomes, we created annual cohorts of the population with diabetes for each year between Apr. 1, 1995, and Apr. 1, 2014. All people from the Registered Persons Database who were Ontario residents eligible for a health card, were alive at the beginning of each year, had a prior diagnosis of diabetes, had had contact with the health care system within the previous 7 years and were aged 105 years or younger were included in the diabetes cohorts.

\section{Covariates}

We described multimorbidity using the Johns Hopkins ACG System (version 7) Aggregated Diagnosis Groups (ADGs) ${ }^{37}$ applied to diagnostic codes associated with hospital admissions and physician services data sources. We classified each person as having a low (0-4 ADGs), medium ${ }^{5-9}$ or high
( $\geq 10$ ADGs) degree of comorbidity. We assigned urban-rural location using the Rurality Index of Ontario, ${ }^{38}$ a broad measure of rurality based on the dissemination area of a person's postal code. A score of 0-9 indicates a major urban centre, a score of 10-39 specifies a nonmajor urban centre (referred to as semiurban), and a score of 40 or greater is considered rural. People with a missing Rurality Index of Ontario score were categorized as "Remote/missing."

\section{Analytic approach}

We calculated annual diabetes prevalence rates using each annual population cohort as the denominator for that year. We calculated the numerator as people in the denominator who received a diagnosis of diabetes on or before the end of the year according to the Ontario Diabetes Database. We calculated diabetes incidence rates in a similar fashion using all newly diagnosed cases in a particular year as the numerator and all people in the annual population cohort with no previous diagnosis of diabetes as the denominator.

To estimate diabetes-specific outcomes, we calculated each outcome measure on an annual basis using each annual diabetes cohort as the denominator for that year. The numerator was people in the denominator who experienced the outcome during the 1 year of follow-up. For rare events, we calculated outcome measures on a 2- or 5-year basis. Definitions for these specific outcomes will be described in detail in each forthcoming paper.

We estimated crude and age- and sex-standardized prevalence and incidence rates and corresponding 95\% confidence intervals among First Nations people and compared them to those among other people in Ontario. We calculated age- and sex-standardized rates, along with $\gamma$-distributed $95 \%$ confidence intervals, ${ }^{39}$ using a direct standardization based on the 2001 Ontario census population to adjust for the differences in population distribution between populations and over time. Among First Nations people, we stratified estimates by those living in or outside First Nations communities, rurality and comorbidity.

Analyses were conducted with SAS Enterprise Guide version 7.1 (SAS Institute).

\section{Ethics approval}

This project was reviewed and approved by the research ethics boards of Queen's University and Laurentian University.

\section{Resullts}

\section{Description of population of First Nations people and other people in Ontario}

Registered First Nations people accounted for 1.2\% of the overall Ontario population ( $n=13406684)$ included in our study cohort. We were able to determine the location of residence (living in or outside a First Nations community) for almost all First Nations people; the 41 people for whom we were unable to determine location of residence are excluded from any analysis stratifying data by First Nations people living in or outside First Nations communities. 
The proportion of First Nations people living in First Nations communities decreased from 36.4\% (52 348/ 143702 ) in $2001 / 02$ to $35.0 \%$ (55 311/158 241) in 2014/15. Compared to other people in Ontario, First Nations people were younger and slightly more likely to be male (Figure 1). Those living in First Nations communities were more likely to be male and were younger than First Nations people living outside these communities (Figure 2).

First Nations people living outside First Nations communities had a higher burden of comorbidity than those living in
First Nations communities (19.1\% v. 13.1\%) (Table 1). Significantly fewer First Nations people than the rest of the Ontario population lived in urban areas (33.1\% v. 73.2\%). Overall, $27.5 \%$ of First Nations people had a Rurality Index of Ontario score of Remote/missing; the values for those living in and outside First Nations communities were $59.9 \%$ and $10.0 \%$, respectively. Almost half (49.7\%) of First Nations people lived in northern areas of the province, compared to $5.5 \%$ of the rest of the Ontario population (data not shown). The proportion of First Nations people across the province is shown in Figure 3.

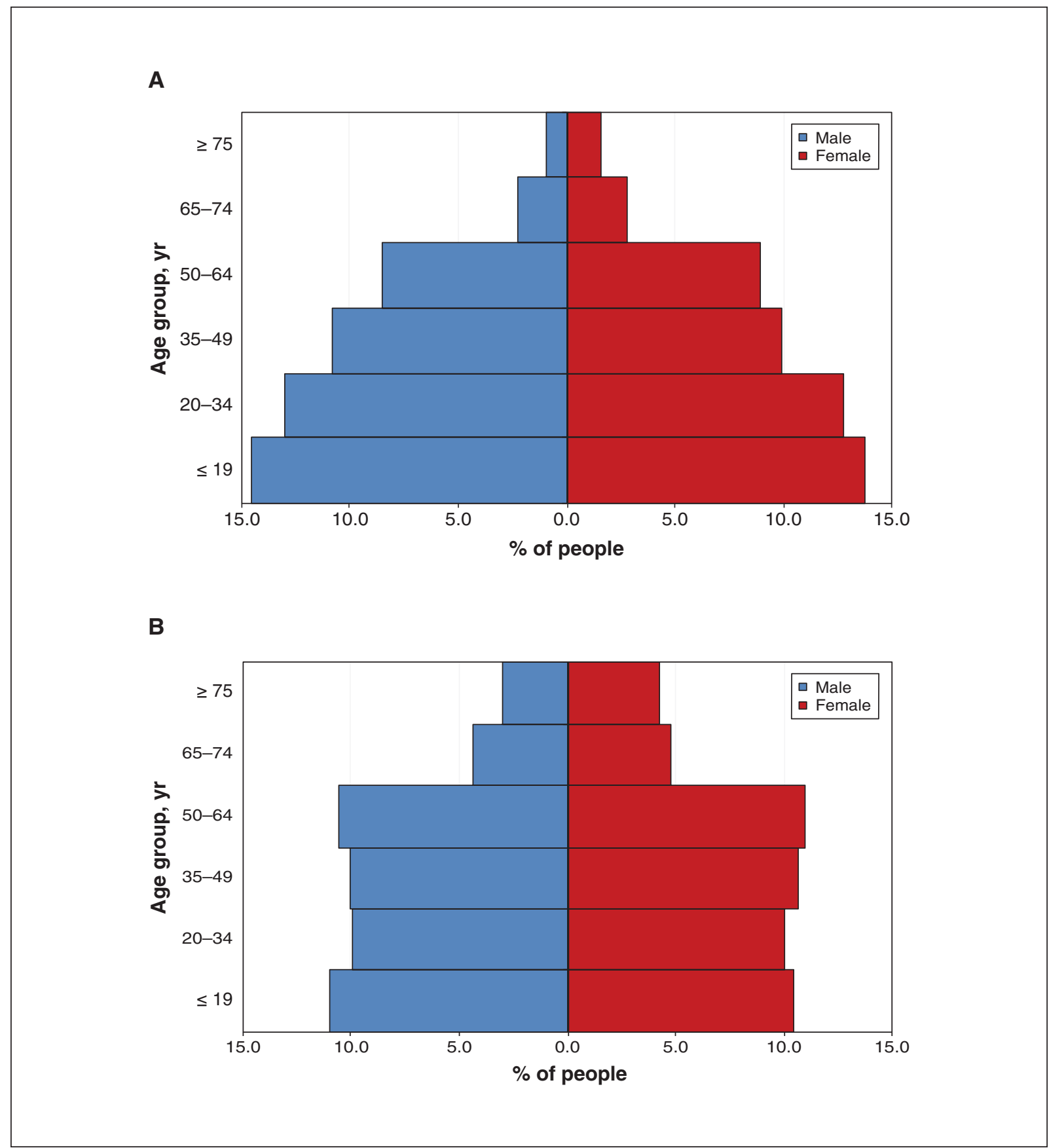

Figure 1: Age distribution of First Nations people (A) and other people (B) in Ontario, 2014/15. 
A

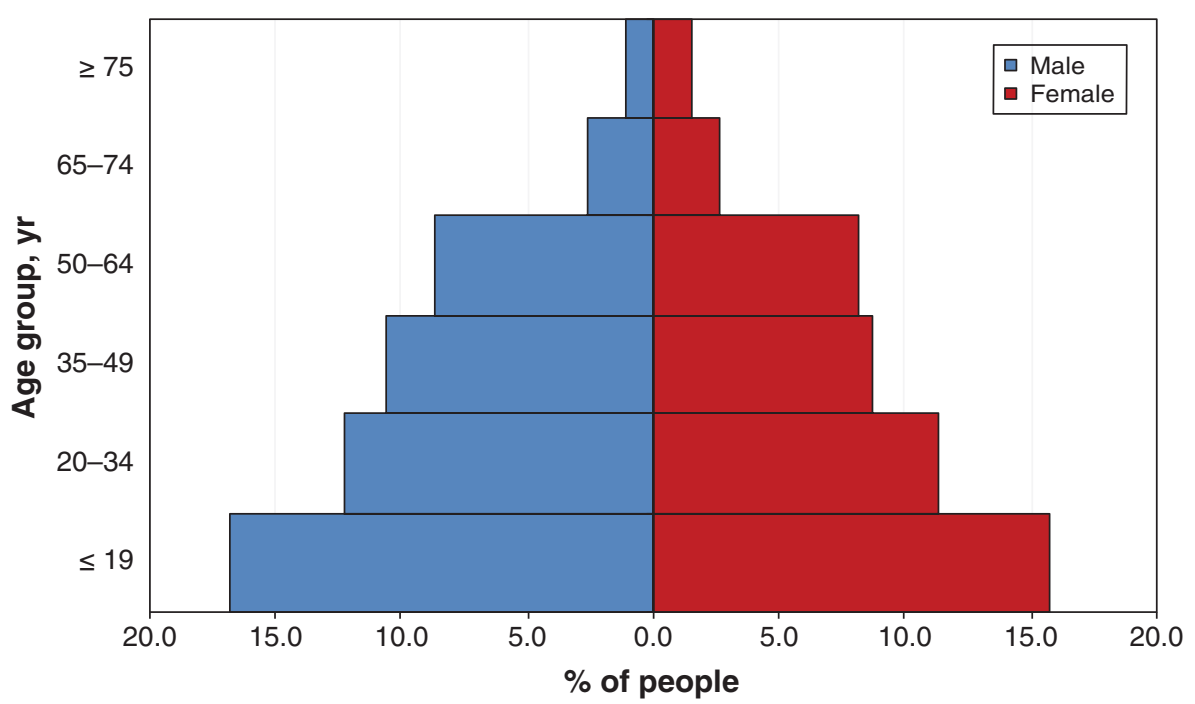

B

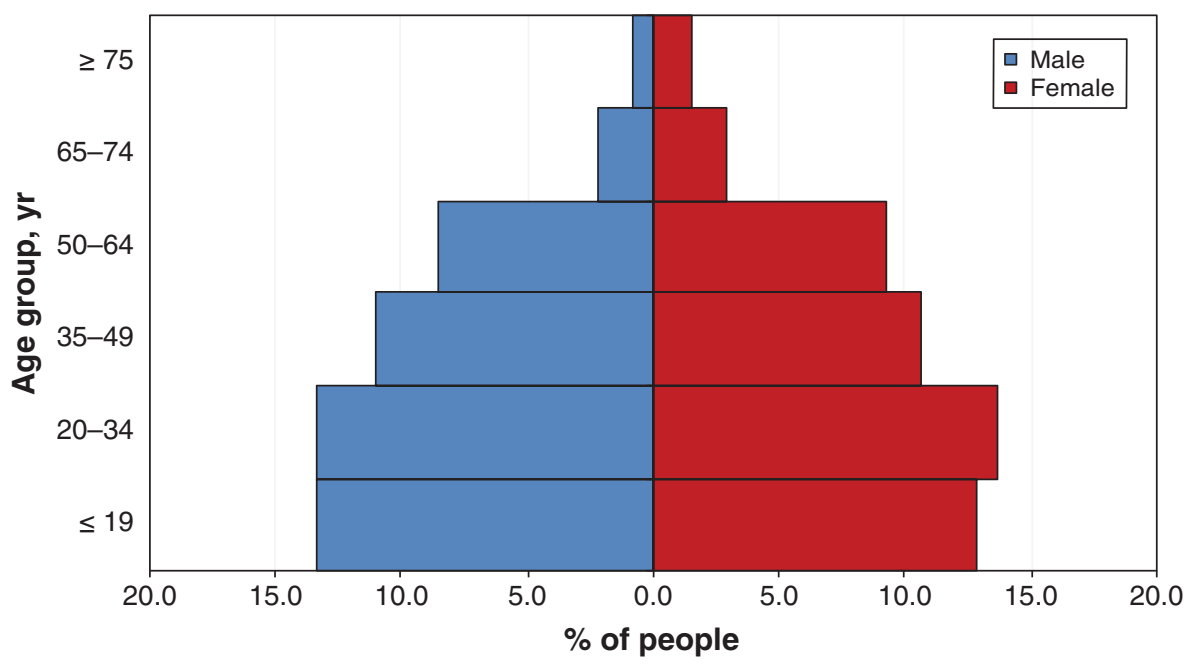

Figure 2: Age distribution of First Nations people living in (A) and outside (B) First Nations communities, 2014/15.

\section{Interpretation}

The age and sex distribution of First Nations people differed from that of other Ontarians. First Nations people tended to be younger and were more likely to live in northern regions of the province and in semiurban, rural or remote areas. Those living in First Nations communities had a lower burden of comorbid disease than those living outside First Nations communities, possibly because they were younger. Also, people may move outside First Nations communities as they age or experience illness to be closer to health care services. First
Nations people with diabetes have noted a lack of health care providers in their communities, which results in the need to travel to receive care. ${ }^{19}$

Our collaborative approach to identifying First Nations people with diabetes in Ontario and describing their access to care and health outcomes is potentially applicable to those working with other Indigenous groups who have access to similar data and need to feel confident that they will be central in deciding how the data are used and how conclusions will be drawn. Although there are provincial and regional differences across Canada, the methods used in 


\begin{tabular}{|c|c|c|c|c|}
\hline \multirow[b]{2}{*}{ Characteristic } & \multicolumn{3}{|c|}{ First Nations people, no. (\%)* } & \multirow[b]{2}{*}{$\begin{array}{l}\text { Other people in } \\
\text { Ontario, no. }(\%)^{*} \\
n=13248443\end{array}$} \\
\hline & $\begin{array}{c}\text { Overall } \dagger \\
n=158241\end{array}$ & $\begin{array}{l}\text { Living in First } \\
\quad \text { Nations } \\
\text { communities } \ddagger \\
n=55311\end{array}$ & $\begin{array}{l}\text { Living outside First } \\
\text { Nations } \\
\text { communities } \ddagger \\
n=102889\end{array}$ & \\
\hline \multicolumn{5}{|l|}{ Age, yr } \\
\hline Mean \pm SD & $34.11 \pm 19.84$ & $33.07 \pm 20.52$ & $34.68 \pm 19.45$ & $40.79 \pm 22.54$ \\
\hline Median (IQR) & $32(18-50)$ & $30(16-49)$ & $32(19-50)$ & $41(22-58)$ \\
\hline \multicolumn{5}{|l|}{ Age group, yr } \\
\hline$\leq 19$ & $44856(28.3)$ & 17965 (32.5) & $26884(26.1)$ & $2829983(21.4)$ \\
\hline $20-34$ & $40855(25.8)$ & 13019 (23.5) & $27815(27.0)$ & 2635661 (19.9) \\
\hline $35-49$ & 32926 (20.8) & 10660 (19.3) & $22258(21.6)$ & $2745274(20.7)$ \\
\hline $50-64$ & 27606 (17.4) & $9324(16.9)$ & $18279(17.8)$ & 2863509 (21.6) \\
\hline $65-74$ & $8060(5.1)$ & $2885(5.2)$ & $5174(5.0)$ & $1213258(9.2)$ \\
\hline$\geq 75$ & $3938(2.5)$ & $1458(2.6)$ & $2479(2.4)$ & $960758(7.2)$ \\
\hline \multicolumn{5}{|l|}{ Sex } \\
\hline Female & 78877 (49.8) & $26557(48.0)$ & $52299(50.8)$ & $6759006(51.0)$ \\
\hline Male & $79364(50.2)$ & $28754(52.0)$ & $50590(49.2)$ & $6489437(49.0)$ \\
\hline \multicolumn{5}{|l|}{ Rurality } \\
\hline Urban & $52343(33.1)$ & $2990(5.4)$ & $49338(48.0)$ & 9693463 (73.2) \\
\hline Semiurban & 30268 (19.1) & $5527(10.0)$ & $24732(24.0)$ & $2545162(19.2)$ \\
\hline Rural & 32134 (20.3) & 13639 (24.7) & $18486(18.0)$ & $941948(7.1)$ \\
\hline Remote/missing & 43496 (27.5) & 33155 (59.9) & $10333(10.0)$ & $67870(0.5)$ \\
\hline \multicolumn{5}{|l|}{ Comorbidity } \\
\hline Low & $71452(45.2)$ & 30635 (55.4) & 40782 (39.6) & $5116120(38.6)$ \\
\hline Medium & $57760(36.5)$ & 17421 (31.5) & 40334 (39.2) & $5605860(42.3)$ \\
\hline High & 29029 (18.3) & 7255 (13.1) & $21773(21.2)$ & 2526463 (19.1) \\
\hline \multicolumn{5}{|c|}{$\begin{array}{l}\text { Note: IQR = interquartile range, } S D=\text { standard deviation. } \\
\text { *Except where noted otherwise. } \\
\text { †This includes all First Nations people included in the Indian Register, regardless of whether we could determine whether they lived within a } \\
\text { First Nations community. } \\
\text { †We were unable to determine location of residence for } 41 \text { people. }\end{array}$} \\
\hline
\end{tabular}

our administrative data analyses are likely applicable to jurisdictions with access to similar data sources.

\section{Limitations}

There are a number of limitations with the administrative health data we used. Population denominators based on the Registered Persons Database do not include people who have had a lapse in their health care coverage, which may lead to overestimation of the rates of diabetes in some regions or communities. Postal codes in the Registered Persons Database are associated with a person's health card and are updated when a health card is renewed (usually every 5 yr) or when a person interacts with the health care system. Therefore, the Registered Persons Database does not have up-todate postal codes for all Ontario residents, and there is a high likelihood that we misclassified the place of residence of some people with high mobility. First Nations people are more geographically mobile than other Canadians, ${ }^{40-42}$ and these inaccuracies in postal codes may have resulted in incorrectly ascribing First Nations people to living in or outside First Nations communities. Last, the Registered Persons Database contains a small number of people who are deceased or no longer living in Ontario, which may slightly underestimate mortality rates.

Our cohort includes only Status First Nations people ${ }^{35}$ and excludes those who are not registered with the federal government or are members of a First Nation that is not recognized by the government of Canada. In addition, we were not able to capture care delivered by community health centres or Aboriginal Health Access Centres, which provide care to $25 \%$ of Indigenous populations in Ontario. ${ }^{43}$ This will result in underestimation of measures of access to primary 


\section{cmaJOPEN}

Research

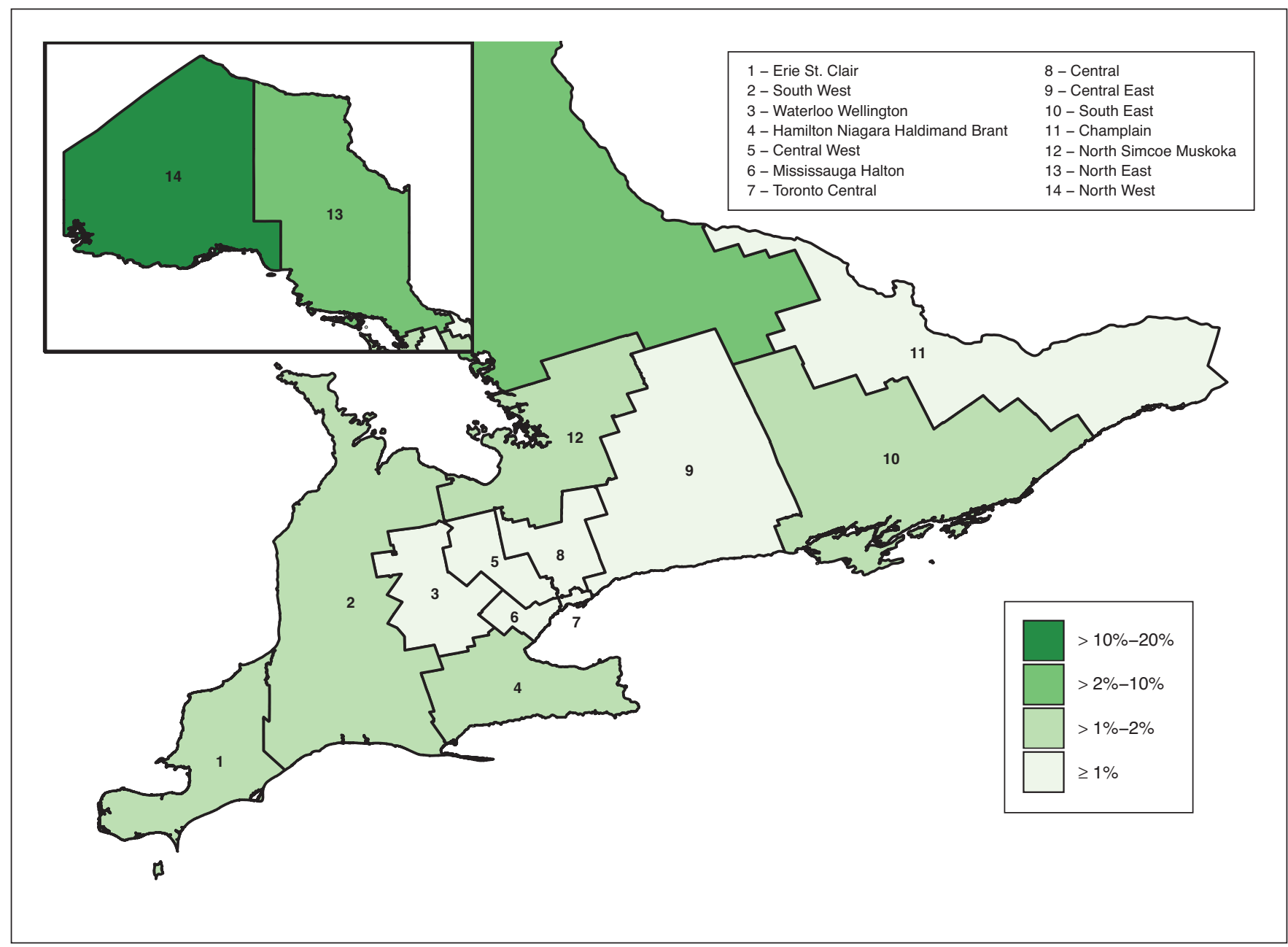

Figure 3: Proportion of the Ontario population identified as Status First Nations, by Local Health Integration Network, 2014/15. Adapted from reference 32 with permission from ICES.

care and outcomes that rely on billing claims by primary care physician (e.g., measures of diabetes control such as glycosylated hemoglobin and lipid monitoring) among patients who used these facilities. In addition, those living in First Nations communities who were treated by nurses working at federally supported nursing stations and health centres will have no physician visit billing claims, which will result in underestimates of access to primary care. This is most relevant in northern Ontario. People living in northwestern Ontario may receive specialist and hospital-based care in Manitoba and, to a lesser extent, those living in southeastern Ontario may receive such care in Quebec. Our data include claims only from Ontario physicians and facilities, so out-ofprovince care has been missed. Many First Nations people live in northwestern Ontario, and this limitation may be important for some diabetes outcome measures, including hospital admissions and visits to endocrinologists. In addition, our measure of multimorbidity relies on diagnostic codes associated with hospital admissions and physician visits, and thus may be underestimated in people who accessed care outside the Ontario system, or in nursing stations or from other nonphysician providers.
Although the algorithm used by the Ontario Diabetes Database to identify people with diabetes has high sensitivity and specificity, ${ }^{36}$ the diagnostic accuracy of the algorithm may be different in First Nations populations. In addition, the database does not capture gestational diabetes ${ }^{44}$ or distinguish between type 1 and type 2 diabetes. Although the majority of people with diabetes have type 2, type 1 accounts for a greater proportion of the diabetes burden among younger people..$^{45}$ This is particularly relevant in First Nations populations, who are younger than other people in Canada. ${ }^{46}$

Income quintiles are a commonly used proxy for individual socioeconomic status. However, this measure is less accurate in rural regions than in urban regions. ${ }^{47}$ Prior work $^{48}$ and preliminary analyses (data not shown) suggest that this proxy method is not sufficiently accurate for use in the Status First Nations population, so we did not include socioeconomic status in these analyses. We also found that the Rurality Index of Ontario score does not perform as well in First Nations populations compared to the rest of the Ontario population. Because the Rurality Index of Ontario is partially based on travel times to the nearest health care centre via roads and highways, fly-in communities are excluded 
from this calculation, as are areas with populations less than 500 and other centres that do not belong to a municipality. ${ }^{38}$ Thus, we included the category "Remote/missing" as a fourth category.

Last, administrative health data do not capture information on other important risk factors for diabetes, such as food security, diet, body mass index, smoking status and physical activity levels, which also influence the outcomes of people with the disease. ${ }^{7}$ These factors are incorporated in our analysis of the First Nations Regional Health Survey (Dr. Laura Rosella, University of Toronto: unpublished data, 2019).

\section{Conclusion}

We identified First Nations people in Ontario using administrative health data and created 2 cohorts with diabetes, First Nations people and other people in Ontario. These cohorts are being used as the basis of a series of studies describing the landscape of diabetes among First Nations people in Ontario. We hope this will help First Nations communities prevent and manage diabetes and cope with the long-term complications of the disease. Because reports often focus on negative findings regarding Indigenous health, ${ }^{49}$ our advisory group communicated the need to ground the findings of this work in the context of the history of First Nations people in Ontario and their experiences with colonization. This is important as we consider how diabetes affects First Nations people compared to other people in Ontario.

\section{References}

1. Diabetes Canada Clinical Practice Guidelines Expert Committee, Houlden RL. Introduction. Can 7 Diabetes 2018;42(Suppl 1):S1-5.

2. Thibault V, Bélanger M, LeBlanc E, et al. Factors that could explain the increasing prevalence of type 2 diabetes among adults in a Canadian province: a critical review and analysis. Diabetol Metab Syndr 2016;8:71.

3. Zhang Q, Wang Y, Huang ES. Changes in racial/ethnic disparities in the prevalence of type 2 diabetes by obesity level among US adults. Ethn Health 2009; 14:439-57.

4. Smith JP. Nature and causes of trends in male diabetes prevalence, undiagnosed diabetes, and the socioeconomic status health gradient. Proc Natl Acad Sci US A 2007;104:13225-31.

5. Menke A, Rust KF, Fradkin J, et al. Associations between trends in race/ ethnicity, aging, and body mass index with diabetes prevalence in the United States: a series of cross-sectional studies. Ann Intern Med 2014;161:328-35.

6. Oggioni C, Lara J, Wells JC, et al. Shifts in population dietary patterns and physical inactivity as determinants of global trends in the prevalence of diabetes: an ecological analysis. Nutr Metab Cardiovasc Dis 2014;24: $1105-11$.

7. Bellou V, Belbasis L, Tzoulaki I, et al. Risk factors for type 2 diabetes mellitus: an exposure-wide umbrella review of meta-analyses. PLoS One 2018;13: e0194127.

8. Fishman EI, Stokes A, Preston SH. The dynamics of diabetes among birth cohorts in the U.S. Diabetes Care 2014;37:1052-9.

9. Lipscombe LL, Hux JE. Trends in diabetes prevalence, incidence, and mortality in Ontario, Canada 1995-2005: a population-based study. Lancet 2007;369: 750-6.

10. Oster RT, Johnson JA, Hemmelgarn BR, et al. Recent epidemiologic trends of diabetes mellitus among status Aboriginal adults. CMA7 2011;183:E803-8.

11. Gregg EW, Cheng YJ, Saydah S, et al. Trends in death rates among U.S. adults with and without diabetes between 1997 and 2006: findings from the National Health Interview Survey. Diabetes Care 2012;35:1252-7.

12. Gulliford MC, Charlton J. Is relative mortality of type 2 diabetes mellitus decreasing? Am 7 Epidemiol 2009;169:455-61.

13. Lind M, Garcia-Rodriguez LA, Booth GL, et al. Mortality trends in patients with and without diabetes in Ontario, Canada and the UK from 1996 to 2009: a population-based study. Diabetologia 2013;56:2601-8.

14. Yu CH, Zinman B. Type 2 diabetes and impaired glucose tolerance in Aboriginal populations: a global perspective. Diabetes Res Clin Pract 2007;78:159-70.

15. Gracey $M$, King M. Indigenous health part 1: determinants and disease patterns. Lancet 2009;374:65-75.
16. Turin TC, Saad N, Jun M, et al. Lifetime risk of diabetes among First Nations and non-First Nations people. CMA7 2016;188:1147-53.

17. First Nations Regional Health Survey (RHS) 2008/10: national report on adults, youth and children living in First Nations communities. Ottawa: First Nations Information Governance Centre; 2012.

18. Dyck R, Osgood N, Lin TH, et al. Epidemiology of diabetes mellitus among First Nations and non-First Nations adults. CMÄ 2010;182:249-56.

19. Jacklin KM, Henderson RI, Green ME, et al. Health care experiences of Indigenous people living with type 2 diabetes in Canada. CMAJ 2017; 189:E106-12.

20. King $M$, Smith A, Gracey $M$. Indigenous health part 2: the underlying causes of the health gap. Lancet 2009;374:76-85.

21. MacDonald C, Steenbeek A. The impact of colonization and Western assimilation on health and wellbeing of Canadian Aboriginal people. Int 7 Reg Local Hist 2015;10:32-46.

22. Reading J. The crisis of chronic disease among Aboriginal Peoples: a challenge for public bealth, population health and social policy. Victoria: Centre for Aboriginal Health Research, University of Victoria; 2009.

23. Feir D, Akee R. First Peoples lost: determining the state of status First Nations mortality in Canada using administrative data. Can 7 Econ 2019;52:490-525.

24. Kirmayer LJ, Dandeneau S, Marshall E, et al. Rethinking resilience from Indigenous perspectives. Can 7 Psychiatry 2011;56:84-91.

25. Cummins S, Curtis S, Diez-Roux AV, et al. Understanding and representing 'place' in health research: a relational approach. Soc Sci Med 2007;65:1825-38.

26. Fitzpatrick SJ, Perkins D, Luland T, et al. The effect of context in rural mental health care: understanding integrated services in a small town. Health Place 2017;45:70-6.

27. Shah BR, Anand S, Zinman B, et al. Diabetes in First Nations people. In: Hux JE, Booth GL, Slaughter PM, et al., editors. Diabetes in Ontario: an ICES practice atlas. Toronto: ICES;2003:13.231-48.

28. Pyper E, Henry D, Yates EA, et al. Walking the path together: Indigenous health data at ICES. Healthc Q 2018;20:6-9.

29. Walker J, Lovett R, Kukutai T, et al. Indigenous health data and the path to healing. Lancet 2017;390:2022-3.

30. Chu A, Han L, Roifman I, et al. Trends in cardiovascular care and event rates among First Nations and other people with diabetes in Ontario, Canada, 19962015. CMA7 2019;191:E1291-8.

31. Walker JD, Rowe R, Jones CR. Describing the process of ethical conduct of research in an Ontario-wide First Nations diabetes research project. CMAf 2018;190(Suppl):S19-20.

32. Green ME, Jones CR, Walker JD, et al., editors. First Nations and diabetes in Ontario. Toronto: ICES; 2019.

33. Ownership, Control, Access and Possession (OCAPTM): the path to First Nations information governance. Ottawa: First Nations Information Governance Centre; 2014.

34. ICES data dictionary. Corporate provider database. Toronto: ICES; 2009. Available: https://datadictionary.ices.on.ca/Applications/DataDictionary/ Default.aspx (accessed 2019 Apr. 24).

35. Indian Act, RSC 1985, c I-5.

36. Hux JE, Ivis F, Flintoft V, et al. Diabetes in Ontario: determination of prevalence and incidence using a validated administrative data algorithm. Diabetes Care 2002;25:512-6.

37. The Johns Hopkins ACG System. Baltimore: Johns Hopkins University. Available: www.hopkinsacg.org (accessed 2019 Apr. 24).

38. Kralj B. Measuring rurality — RIO2008_BASIC: methodology and results. Toronto: Ontario Medical Association; 2009.

39. Fay MP, Feuer EJ. Confidence intervals for directly standardized rates: a method based on the gamma distribution. Stat Med 1997;16:791-801.

40. Cooke M, Belanger D. Migration theories and First Nations mobility: towards a systems perspective. Can Rev Sociol Anthropol 2006;43:141-64.

41. Migration and mobility of Canada's Aboriginal population. Ottawa: Canada Mortgage and Housing Corporation; 1996.

42. Snyder M, Wilson K. Urban Aboriginal mobility in Canada: examining the association with health care utilization. Soc Sci Med 2012;75:2420-4.

43. Aboriginal Health Access Centres and Aboriginal community bealth centres: report to communities (2016). Toronto: Alliance for Healthier Communities; 2016.

44. Booth GL, Luo J, Park AL, et al. Influence of environmental temperature on risk of gestational diabetes. CMA7 2017;189:E682-9.

45. Dabelea D, Mayer-Davis EJ, Saydah S, et al.; SEARCH for Diabetes in Youth Study. Prevalence of type 1 and type 2 diabetes among children and adolescents from 2001 to 2009. 7AMA 2014; 311:1778-86.

46. Aboriginal peoples in Canada: key results from the 2016 census. Ottawa: Statistics Canada; 2017. Available: www150.statcan.gc.ca/n1/daily-quotidien/171025/ dq171025a-eng.htm (accessed 2018 July 31).

47. Trends in income-related bealth inequities in Canada: methodology notes. Ottawa: Canadian Institute for Health Information; 2015.

48. Chiefs of Ontario; Cancer Care Ontario; Institute for Clinical Evaluative Sciences. Cancer in First Nations people in Ontario: incidence, mortality, survival and prevalence. Toronto: Cancer Care Ontario; 2017.

49. Cochran PA, Marshall CA, Garcia-Downing C, et al. Indigenous ways of knowing: implications for participatory research and community. Am 7 Public Health 2008;98:22-7. 
Affiliations: Department of Family Medicine (Slater, Green) and ICES Queen's (Slater, Green, Khan), Queen's University, Kingston, Ont.; Department of Medicine (Shah), University of Toronto; ICES (Shah, Walker); Chiefs of Ontario (Jones, Sutherland), Toronto, Ont.; Memory Keepers Medical Discovery Team (Jacklin), Department of Family Medicine and Biobehavioral Health, University of Minnesota Medical School, Duluth, Minn.; School of Rural and Northern Health (Walker), Laurentian University, Sudbury, Ont.

Contributors: Michael Green, Baiju Shah, Carmen Jones, Roseanne Sutherland, Kristen Jacklin and Jennifer Walker conceived and designed the study. Shahriar Khan analyzed the data. Morgan Slater drafted the manuscript. All of the authors contributed to data interpretation, revised the manuscript critically for important intellectual content, approved the final version to be published and agreed to be accountable for all aspects of the work.

Funding: This study was supported by an Ontario SPOR SUPPORT Unit IMPACT Award. Additional support was provided to Michael Green through the Brian Hennen Chair in Family Medicine, Queen's University, to Jennifer Walker through a Tier 2 Canada Research Chair in Indigenous Health and by ICES, which is funded by an annual grant from the Ontario Ministry of Health and Long-Term Care. Morgan Slater was supported by a Health Systems Impact Fellowship from the Canadian Institutes of Health Research.

Acknowledgements: The authors' partner through the early design, implementation and final dissemination of this project is the Chiefs of
Ontario. Their many member contributions were key to this project. The authors acknowledge the members of the Patient Advisory Committee for their insightful and thoughtful input; their advice made an important contribution to the work. For a complete listing of the members of the committee, see the full report. ${ }^{32}$ The authors also acknowledge the First Nations people from Big Grassy River First Nation, Alderville First Nation, Caldwell First Nation, Six Nations of the Grand River and Moose Cree First Nation with diabetes who shared their personal experiences. The authors also thank Sue Schultz for developing the methodology to identify where First Nations people live, Rahim Moineddin for his guidance on statistical analyses, Paul Nguyen for creating maps to show the distribution of the population across the province and IMS Brogan for use of their Drug Information Database.

Disclaimer: Parts of this material are based on data and information compiled and provided by the Canadian Institute for Health Information, Cancer Care Ontario and the Ontario Ministry of Health and LongTerm Care (MOHLTC). This study was supported by ICES, which is funded by an annual grant from the Ontario MOHLTC. The analyses, conclusions, opinions and statements expressed in this article are those of the authors and are independent from the funding or data sources. No endorsement by ICES or the Ontario MOHLTC is intended or should be inferred.

Supplemental information: For reviewer comments and the original submission of this manuscript, please see www.cmajopen.ca/content/7/4/ E680/suppl/DC1. 